\title{
José Vicente Asuar: el compositor virtuoso
}

\author{
Planté...construí...escribí.. \\ nada excepcional, \\ otros lo han hecho mejor que yo, \\ pero lo hice. \\ (José Vicente Asuar) ${ }^{1}$
}

Probablemente todos los seres humanos nos preguntamos qué quedará de nuestro paso por la vida. Qué -de lo que hicimos y lo que no hicimos-retendrán para recordarnos nuestros descendientes, amigos, colegas y en algunos casos, personas que ni siquiera conocimos. ¿Habremos contribuido en algo, por pequeño que sea, para que nuestro mundo sea un poco mejor?

En el caso de José Vicente Asuar, pareciera que la historia -que nunca la escribe uno mismo, al menos no sobre sí mismo- ya ha establecido de modo indeleble por lo que será recordado: las Variaciones espectrales, la primera obra electrónica chilena y el COMDASUAR, el primer computador musical. Al menos es ello lo que se cita y se recuerda hoy artículo tras artículo, entrevista tras entrevista. Con justa razón, claro. Ambos trabajos fueron proezas de creatividad, invención, ingenio en un mundo mucho más aislado de lo que es hoy.

Sin embargo, me gustaría evocar otros aspectos de lo que querría que también fueran retenidos por la historia. De su obra y su persona. Tal vez el escribirlo ayude en ello. Tal vez el escribirlo también me ayude: no hay sonido ni texto detrás del cual alguien no se devele. ¿Será posible develar a Asuar sin develarme yo mismo?

1 Todas las citas de José Vicente Asuar provienen del texto Anécdotas y pensamientos, no publicado, para lo que se cuenta con la amable autorización de sus hijos Malise y Claudio Asuar. Las citaciones corresponden a los capítulos titulados "El porqué del abandono" (fechado en 2012), "Música existencial" (s/f. b) y "Mis últimos años" (s/f. c)

Revista Musical Chilena, Año LXXI, enero-junio, 2017, Nº 227, pp. 265-272 


\section{Acordal: asuntos de Pájaros}

Guararia Repano fue compuesta en 1968 en Caracas, durante su estadía de casi tres años en la capital de Venezuela, como encargado de diseñar y construir un estudio de grabación, para lo que fue contratado por la Comisión de Estudios Musicales del Instituto Nacional de Cultura y Bellas Artes de Venezuela. Los materiales sonoros de esta obra provienen esencialmente de sonidos electrónicos, una melodía de los pueblos originarios guajiros y de grabaciones de cantos de aves de la selva del Amazonas. Hay al menos cuatro obras de Asuar donde aparecen cantos de aves, entre ellas figura Affaire des Oiseaux (1975), compuesta exclusivamente con grabaciones de estos cantos. En la Guararia hay cruce, hibridación, dificultad para distinguir entre un material y otro, pues los cantos parecen electrónicos y a veces los sonidos electrónicos parecen aves. Por el contrario, en Affaires solo hay pájaros. Sorprendentes sonidos de cantos de aves entremezclados, apenas transformados electrónicamente, un Arte de Pájaros Nerudiano o tal vez, una versión sonora del Pajarístico, de Juan Luis Martínez. ¿Cómo surge esta obsesión de Asuar por el canto de las aves?

'En una ocasión hace ya muchos años, en el norte de Argentina, en una zona selvática, tuve una experiencia inesperada y alucinante: $\mathrm{Al}$ atardecer, caminando a través de una selva tupida, inmerso entre árboles que permitían ver el cielo solo a pedacitos, empezaron a surgir de todas partes cantos de pájaros. Seguramente despedían el día o quizás llamaban a sus parejas para reunirse en el nido o en otros lugares secretos. Entre toda la vocinglería destacaba especialmente una raza de pájaros cuyo canto semejaba un lamento humano. Empezaba el lamento en un tono agudo y desde allí bajaba lentamente en un glisando a tonos más bajos. Cada pájaro tenía un lamento distinto: algunos más agudos, otros más graves, algunos glisandos muy largos, otros más breves, y finalmente la resolución del glisando distinta en cada pájaro. Poco a poco los pájaros 'lamentantes' se fueron adueñando del espacio sonoro y me brindaron un concierto maravilloso. Un concierto en el que sus ejecutantes eran invisibles. No pude ver a ningún pájaro. Ni siquiera supe cómo eran. Pero sí pude identificar ciertos lamentos y su ubicación en el intrincado espacio que me rodeaba" (Asuar s/f. a: 2).

El relato recién citado se complementa con el de otras situaciones sonoras que Asuar evoca con la misma pasión y que califica como experiencias conmovedoras en su relación con el sonido: la escucha del mar y el sonido del tumulto en medio de una manifestación política en Argentina. Lo que me parece que une a estos tres casos tan dispares, es la pregunta acerca de lo que es música y de cómo es posible encontrarla en situaciones que a priori no son musicales.

Asuar se solaza escuchando estas sinfonías de ruidos, tratando de entender esa aparente cacofonía sonora, pues él no cree en el caos. "En la música de los pájaros somos nosotros los que penetramos en otro mundo que existe a nuestro lado y que hemos abandonado e ignorado", escribe. Me interesa destacar el nosotros: escuchar al mundo, escuchar al otro es escucharse a sí mismo, diría Nancy (2008). Es el Ser que resuena, seguramente acotarían Heráclito y Barthes. En la fascinación por la escucha del mundo, me parece entrever en Asuar la conmoción del descubrirse, del conocernos y conocerse. 
Cuando escuchamos, lo que escuchamos -no lo que suena- algo nos dice de nosotros mismos. ¿Qué de sí mismo descubrió Asuar cuando escuchaba sus aves, el mar o a la multitud? Tal vez entrevió que lo que logramos concebir como música también nos habla de cómo entendemos la existencia humana; qué ella -la música- nos refleja y por medio de ella -lo que entendemos como música- es el mundo el que se nos revela, pues "en solo un minuto habremos escuchado toda una eternidad", afirma Asuar.

¿Cómo no imaginar entonces que en el canto de un pájaro se resume tal vez el canto de todos los pájaros, que en el romper de una ola se contienen todos los mares del mundo, y que en la voz del otro también resuena la nuestra? ¿Están entonces en las aves que se escuchan en En el jardín (1985), todos los cantos pajarísticos que alguna vez Asuar escuchó y que le revelaron que la música también podía ser aquello que no parecía serlo?

"La música existe solo cuando se la busca", me responde Asuar. Solo cuando se la busca... Esta afirmación me sugiere una frase que se me viene ahora a la mente: no hay música si alguien que la musiquee $e^{2}$. Y musiquear es lo que hacemos cuando escuchamos, componemos, tocamos, tarareamos o danzamos lo que suena. Sea canto de pájaros, las olas del mar o la Guararia Repano.

\section{Obsesiva: érase una vez...}

Diálogos (1985) es la primera obra que escuché de Asuar, el año de su composición, en los míticos conciertos de la Asociación Anacrusa en el Goethe Institut de la calle Esmeralda. Años más tarde leí que esa obra estaba construida a base de una serie de 48 sonidos. No obstante, por más que la oigo y a pesar de una gestualidad instrumental, no podría calificar a esta obra de serial. Sí escucho la síntesis FM del Yamaha DX7. Sí escucho la síntesis aditiva del COMDASUAR. Sí escucho las modulaciones de frecuencia que me fascinan en Elegía (1982). Imagino cómo debieron resonar estas obras en el estudio de calle San Antonio, donde Asuar se refugió luego de abandonar la Facultad de Artes.

Durante la década de los ochenta, Asuar había logrado implementar un dispositivo de composición integrado por el COMDASUAR, como módulo central, un computador Atari, el Yamaha DX7 más otros módulos de síntesis y periféricos. El dispositivo era controlado desde el COMDASUAR por medio de las instrucciones de programas que había diseñado Asuar. "Era un sistema diseñado por mí, para mí, y para mis obras". Algo cercano a la felicidad para quien había sido ungido desde su juventud con estas dos palabras: ingeniero, músico.

"El lenguaje para expresarme constaba de 256 instrucciones, 256 palabras. El lenguaje musical de Mozart consistía en una escala de doce sonidos cada uno dando origen a una tonalidad con sus relaciones melódicas y acórdicas: doce acordes mayores, doce acordes menores y otros acordes más complejos con distintas posiciones y con sonidos

2 Musiquear podría ser el término en castellano equivalente para Musicking, que plantea Krueger (2014). 
agregados dentro de cada tonalidad. O sea, también Mozart disponía de un lenguaje compuesto por un número finito de elementos silábicos. En mi lenguaje yo podía componer un programa definiendo una sucesión de instrucciones que realizaran una actividad coherente. Podía crear un ente abstracto que al aplicarlo en entes físicos producía efectos" (Asuar 2012: 42).

Lo que Asuar comenzó a desarrollar -tal vez desde sus primeros contactos con la informática-, y que funcionaba a pleno régimen en el estudio de calle San Antonio, fue un dispositivo tecnológico diseñado para responder a los requerimientos de un sistema de composición. Para diseñar un sistema de composición imagino que Asuar pudo hacerse la pregunta ¿cómo un creador (en este caso él mismo) compone?. No cuándo. No qué. Sino cómo. ¿Cómo surgen mis ideas? ¿Cómo las resuelvo? ¿Con qué herramientas...? Un dispositivo de composición desarrollado para responder a un sistema de composición es un signo de madurez musical, resultado del conocerse.

Si se escucha la trama compleja que da inicio a Elegía, que evoluciona en el grave de la tesitura y poco a poco se le van adicionando parciales que enriquecen el espectro, aunque no linealmente, en un crescendo armónico que se extiende hasta los tres minutos de la obra. Ahora, si se escucha casi la misma trama al inicio de Diálogos. Es cierto que no tiene la importancia formal de aquella de Elegía, en este caso se trata solo de una apertura; pero se puede notar cómo suenan diferentes, el grano de la voz ha cambiado. Entre ambas obras hay tres años de distancia $\mathrm{y}$ tres años de perfeccionamiento del sistema y dispositivo.

"Eran programas para crear música. Programas que manipulaban juegos y probabilidades sin que yo pudiera saber de antemano el resultado sonoro o musical que me darían. Eso era lo interesante del sistema: Una vez introducido el programa, el computador hacía cálculos que yo desconocía y entregaba como resultados una sucesión de sonidos que podrían ser ideas o fragmentos sonoros para ser utilizados en una composición más elaborada. No entregaba listados o informaciones en una pantalla, sino entregaba de inmediato, sin necesidad de espera, constelaciones de sonidos, imprevisibles, irrepetibles, distintas cada vez que comenzaba la ejecución del programa. Había programas para 'descubrir' alguna música que pudiese emerger de las propuestas sorprendentes, inesperadas, algunas veces disparatadas, que entregaba el computador. También habían programas diseñados para ayudarme a la creación en algunas ideas específicas y también otros programas que apuntaban a descubrir algunas de las fuerzas subconscientes que actúan en el acto creativo, una especie de espejo que reflejara la forma cómo un compositor enfrenta la creación musical: Una mente caótica posiblemente crearía programas caóticos. Una mente ordenada, programas ordenados. Una mente genial, mozartiana, crearía seguramente programas que darían resultados finos, potentes, llenos de posibilidades de desarrollo" (Asuar 2012: 43).

No es difícil imaginar el placer, el entusiasmo infinito de un compositor que se encuentra en pleno dominio de su dispositivo y sistema: "Hubo una época en la que permanentemente estaba ensimismado pensando el programa que iba a hacer cuando llegara al Estudio". Si consideramos la tesis de la mente extendida (Clarck y Chalmers, 1998), compositor y dispositivo forman 
un todo, un sistema acoplado que no puede funcionar el uno sin el otro. Y tal vez ello explique en parte que Asuar deje de componer: "Después se acabó por agotamiento de las capacidades del sistema. Empecé a repetirme, el factor sorpresa o imprevisibilidad que tanto me interesaba ya no aparecía. El estudio me quedaba chico para mis aspiraciones, la capacidad de memoria de mi sistema era ridículamente pequeña y me impedía realizar programas de cierta complejidad”. El sistema se desacopló.

\section{Evocativa: en el infinito}

En la soledad de mi estudio en los años 80 mi único contacto era con el extranjero (2012 pp. 48).

Las Cuatro piezas instrumentales (1989), última obra que compuso Asuar, fue recibida con sorpresa en el medio de la música electroacústica. La modelización por síntesis de sonidos instrumentales tenía un interés esencialmente en la investigación, no en la creación, pues ¿para qué producir por síntesis algo que ya existía acústicamente y que como tal, sonaba infinitamente mejor que su equivalente sintético? En las cuatro piezas instrumentales escuchamos a una trompeta, una marimba, una guitarra y un arpa, que hoy, en la época del muestreo, nos parecen de poca calidad. Calidad General MIDI, diríamos. Probablemente Asuar imaginó que ya se había logrado la suficiente capacidad de cálculo informático como para modelizar fielmente los sonidos instrumentales. Supongo que eso es lo que pensaba Asuar con esta obra, que era una de las posibles direcciones de investigación en síntesis de sonido, aunque lo que finalmente se impuso fue el muestreo.

Pienso que esta última obra, tan distinta a su trabajo anterior, tal vez haya sido por lo mismo, concebida como despedida. Asuar entendía que ya estaba llegando a un punto límite en lo que eran sus posibilidades de seguir avanzando. Solo. "Y me detuve porque para seguir mi labor creativa necesitaba desarrollar un nuevo sistema con tecnologías que no dominaba (...) entraba a otra categoría tecnológica: la música digital", confiesa. Imagino que de haberse encontrado Asuar en otro espacio que en la soledad de su estudio, con compañía y apoyo entre colegas e instituciones musicales, otra podría haber sido la dirección que tomara. A pesar de su natural tendencia hacia el trabajo en solitario, al ensimismamiento, Asuar sabe que la velocidad y complejidad con que se desarrollan los cambios tecnológicos en la era digital necesita de equipos de trabajo. Y en Chile, no los tiene. "Había predicado en el desierto".

Desde que Asuar renunció a la dirección del Laboratorio de Fonología Musical radicado en la Facultad de Artes y Ciencias Musicales en 1975, se recluyó en su laboratorio, primero en su casa, luego en la calle San Antonio. Las razones del alejamiento de la Facultad y luego del mundo académico musical chileno son múltiples y complejas. Samuel Claro, decano de aquella época, quería nombrar como director del laboratorio a Juan Lémann, quien tenía escaso conocimiento de la disciplina y que no había demostrado interés hasta ese momento por la música electroacústica. 
Asuar entendió que se trataba de una crítica -para él injusta-, del modo en que se había desarrollado el laboratorio bajo su dirección, y que tras este nombramiento se encontraba Juan Amenábar. La inquina entre ambos había estallado en 1968, a raíz de la creación de la carrera de Tecnología del Sonido que le fue encargada a Asuar. En una entrevista aparecida en la revista Zona de Contacto (2002), Asuar relata la siguiente versión de lo ocurrido: "Cuando me pidieron crear Tecnología en Sonido en la Chile, le propuse a Amenábar que trabajáramos juntos, pero él reaccionó muy extraño, como indiferente. Después, me mostraron una carta de Amenábar donde él se ofrecía para hacerse cargo de la nueva carrera".

A la larga, Amenábar se hizo cargo del laboratorio. Comenzó a hacerse pedagogía en él, pero no hubo más investigación. Al contrario, con Asuar, hubo investigación, pero no pedagogía. A mediados de 1982, el laboratorio que tantos años había costado instalar desaparece. La verdad es que nadie sabía ocupar satisfactoriamente ni el ARP 2600 ni los módulos Moog. Por falta de uso y cuidado se deterioran y quedan arrumbados en algún rincón de una sala. Así los vi en 2005. Así me imagino que están todavía hoy.

Quienes lo buscábamos afanosamente en 2005 encontramos al Asuar de casi quince años después de dejar la música. ¡Pasan tantas cosas en la vida durante quince años!. Encontramos a un Asuar sorprendido, un tanto desconfiado, divertido observando a estos jóvenes -y otros no tanto- que lo apabullábamos a preguntas. Pensábamos que teníamos una deuda con la historia que saldar o tal vez, que la historia tenía una deuda con nosotros. Había tan poco tangible a lo que hacer referencia, éramos como unos huérfanos de la electroacústica, ni nuestros antecesores ni su historia se conectaban con nosotros. Aún. José Vicente Asuar era el eslabón que necesitábamos, el que unía la cadena desde el inicio hasta el momento en que nosotros comenzamos a ser parte de ella. Y lo hizo. Recuerdo un concierto de Ai-Maako en 2012, estaban allí Asuar, Gabriel Brnčić y el más joven de los miembros de la CECh en aquella época, Andrés Mondaca, quien no debía tener entonces más de 20 años. Allí estuvo la cadena completa. No había predicado en el desierto.

El Asuar que encontramos estaba sorprendido y curioso de lo que estaba sucediendo. Curioso y sorprendido por el interés que nosotros y luego tantos otros le manifestamos. Nos repetía: "mi amor por la música no fue los suficientemente fuerte, por eso la dejé”. Es cierto que algo de amargura había en esa declaración. En una entrevista que le hice en 2008 o 2009 me lo dijo. Ello definió el final de la entrevista, pues nos inundó la emoción. Sin embargo, creo que él ya había hecho la paz con su vida. Había amado la música mucho y muy intensamente, sin embargo la vida a veces nos separa de nuestros más grandes amores. Tal vez sabiamente.

\footnotetext{
"Ninguna otra alternativa para continuar creando música me interesaba. Era un ingeniero-músico y lo que me animaba era seguir creando en ambos sentidos. Crear un nuevo tipo de música estrechamente unido a un nuevo sistema tecnológico. Crear algo nuevo y descubrir sus capacidades desde un principio. Si no podía continuar en esa dinámica creativa no tenía sentido ni atractivo seguir haciendo "música, seguir dando vueltas por sistemas ya utilizados. No..., eso no" (Asuar 2012: 49).
} 
Preguntaba algunas líneas atrás qué de sí mismo había descubierto Asuar mientras escuchaba a sus aves, al mar o a la multitud y creo que se resume en lo siguiente: su doble condición de ingeniero y músico. No podía ser lo uno sin lo otro. Esa dualidad en realidad era la unicidad que lo definía como persona y a ello había que ser fiel. Me parece que ese fue el amor de su vida, y a ese amor sí lo amó.

"Amé y fui amado. Quise ser músico y lo fui. Quise ser ingeniero y lo fui. Quise saber de todo y supe de todo. Quise viajar y viajé. Quise crear cosas y las creé. Quise tener descendencia y la tuve. Quise ser libre y fui libre. Quise ser independiente y desde los 26 años nunca hubo nadie que mandara en mi vida" (Asuar s/f c: 1).

Estoy seguro: amó al amor de su vida.

\section{REFERENCIAS BIBLIOGRÁFICAS}

Asuar, José Vicente

s/f. a Anécdotas y pensamientos. Archivo personal del autor

s/f. b Música existencial. Archivo personal del autor.

s/f. c Mis últimos años. Archivo personal del autor.

2012 El porqué del abandono. Archivo personal del autor.

BARTHES, ROLAND

1986 Lo obvio y lo obtuso. Barcelona: Paidós.

Clark, Andy y Chalmers, David

1998 “The Extended Mind”, Analysis LVII/1 (enero), pp. 7-19.

Gallegos, Álvaro

2013 José Vicente Asuar habla del creciente interés en su obra. beethovenfm.cl.

http://www.beethovenfm.cl/jose-vicente-asuar-habla-del-creciente-interes-en-suobra/ Recuperado el 16/02/2017.

Krueger, JoEL

2014 "Affordances and the Musically Extended Mind", Frontiers in Psychology, IV/1003 (enero), pp. 1-12.

Nancy, Jean LuC

2008 A la escucha. Buenos Aires: Amorrortu.

RIVERA, JORGE

2006 Heráclito. El esplendente. Santiago de Chile: Brickle Ediciones.

SChumacher, Federico

2005 La música electroacústica en Chile: 50 años. Recuperado desde https://www. researchgate.net/publication/260386453_LA_MUSICA_ELECTROACUSTICA_ EN_CHILE el 16/02/2017.

2007 “50 años de música electroacústica en Chile”, Revista Musical Chilena, LXI/208 (julio-diciembre), pp. 66-81. Disponible en www.revistamusicalchilena.uchile.cl 
Zona de Contacto, El Mercurio

2002 La prehistoria de la electrónica chilena. Recuperado desde http:/ /www.ceo.cl/609/ printer-14589.html el 16/02/2017.

Federico Schumacher Ratti

Compositor e investigador

Facultad de Psicología

Universidad Diego Portales 